\title{
Oral Health and nutritional status in nursing home residents-results of an explorative cross-sectional pilot study
}

\author{
Dirk Ziebolz ${ }^{1 *+} \mathbb{D}$, Christine Werner ${ }^{2 \dagger}$, Gerhard Schmalz ${ }^{1}$, Ina Nitschke ${ }^{3,6}$, Rainer Haak ${ }^{1}$, Rainer F. Mausberg ${ }^{4}$ \\ and Jean-François Chenot ${ }^{5}$
}

\begin{abstract}
Background: This study was performed to assess oral and nutritional status of nursing home residents in a region of Lower Saxony, Germany. The aim was to show potential associations between oral status (dentate or edentulous) , further anamnestic factors (dementia, age, smoking) and the risk for malnutrition in this population.

Methods: In this observational cross-sectional pilot study of residents from four nursing homes Mini Nutritional Assessment (MNA), Body-Mass-Index (BMI), dental status (DMF-T) and periodontal situation (PSR /PSI) were recorded. Associations of recorded factors with oral health and nutritional status were examined in univariate and multivariate analysis.

Results: Eighty-seven residents participated in the study (mean age: 84.1 years; female: 72\%, demented: 47\%). Average BMI was $26.2 \mathrm{~kg} / \mathrm{m}^{2}$; according MNA $52 \%$ were at risk for malnutrition. $48 \%$ of the residents were edentulous, and the average DMF-T of dentulous was 25.0 (3.7) (D-T: 2.0 [3.1], M-T: 15.0 [8.3], F-T: 8.0 [7.4]); PSR /PSI 3 and 4 (need for periodontal treatment) showed $79 \%$ of residents. In univariate analysis dementia (OR $2.5 \mathrm{Cl}_{95}$ 1.15.6) but not being edentulous (OR $2.0 \mathrm{Cl}_{95}$ 0.8-5.8) were associated with being at risk for malnutrition. Dementia remained associated in multivariate analysis adjusting for age and sex, (OR $3.1 \mathrm{Cl}_{95}$ 1.2-8.2) and additionally being edentulous (OR $2.8 \mathrm{Cl}_{95}$ 1.1-7.3) became associated significantly. Furthermore, nursing home residents with dementia had more remaining teeth (OR $2.5 \mathrm{Cl}_{95}$ 1.1-5.9).
\end{abstract}

Conclusion: Dementia was a stronger predictor for risk of malnutrition in nursing home residents than being edentulous. Further studies to elucidate the possible role of oral health as cofactor for malnutrition in dementia are needed.

Keywords: Oral health, Nutritional status, Nursing home, Dementia

\section{Background}

Oral health situation of nursing home residents is often poor due to age and limited access to dental care. This might be a symptom as well as a cause of poor general health and nutritional status [1,2]. Due to demographic and societal changes it is expected that the number of elderly people in nursing homes will increase [3]. Although the number of edentulous people is increasing

\footnotetext{
* Correspondence: dirk.ziebolz@medizin.uni-leipzig.de

${ }^{\dagger}$ Equal contributors

${ }^{1}$ Department of Cariology, Endodontology and Periodontology, University of Leipzig, Liebigstr. 12, D 04103 Leipzig, Germany

Full list of author information is available at the end of the article
}

with age, many of these nursing home residents have remaining teeth [4]. This might be due to advances in prevention and improved oral hygiene [5]. Corresponding developments have already been shown for elderly German individuals in the fourth German oral health study [6]. Many nursing home residents are unable to practice oral hygiene because of physical or cognitive disabilities. However, the oral health care support in nursing homes is often limited resulting in poor oral hygiene and oral health $[7,8]$. These hygienic deficits affect not only teeth but also prostheses [9]. Furthermore, elderly nursing home residents are partly unable to communicate their oral health problems to nursing staff or 
show defensiveness [10]; so most interventions are only carried out if there is pain [10].

Moreover, nutrition has an important role in quality of life, especially among the elderly, and food intake has a tremendous influence on morbidity and mortality [11]. There is evidence that poor oral health, xerostomia and reduced chewing ability cause involuntary weight loss in the elderly population [12]. In this context, oral health and dental status have an influence on the nutritional status of residents [13]. Tooth loss, in particular, leads to loss of chewing function and thus, causes residents' avoidance of food, as it is difficult to chew foods like fruits and vegetables [14]. In this manner, poor oral status and insufficient prosthetic restorations might be one of the important risk factors for malnutrition in nursing homes.

However other risk factors for malnutrition in older adults are depression, cognitive impairment, dementia, functional impairment, and swallowing difficulty $[15$, 16]. Dementia and also cognitive impairment might also have an influence on oral conditions. Accordingly, demented nursing home residents show higher periodontal treatment need $[17,18]$. Especially the association between cognitive impairment and tooth loss has been discussed, showing heterogeneous results [19-22]. Although the fifth German oral health study (DMS V) has investigated nursing home residents for the first time in a representative population study in Germany [23], only few studies on oral health in this patient group in Germany are available [1, 17]. It was hypothesized that both, dementia and being edentulous are predictors for the risk for malnutrition. Furthermore, the relationship of oral health and other factors like dementia in nursing home residents should be explored.

Therefore, this study was performed to assess oral health (dental and periodontal condition) and nutritional status of nursing home residents in a region of Lower Saxony, Germany. The aim was to investigate potential associations between oral status (dentate or edentulous), further anamnestic factors (dementia, age, smoking) and the risk for malnutrition in this population.

\section{Methods}

This was a observational cross sectional pilot study with elderly individuals dwelling in nursing homes in Northern Germany conducted between March and August 2011. This study was reviewed and approved by the ethics committee of the University Medical Center Goettingen, Germany (No. 21/3/10). Nursing home residents or their legal guardian were informed verbally and in writing about the study and gave written informed consent.

\section{Participants}

A total of 370 elderly individuals living in four different nursing homes in south lower Saxony (area of
Goettingen and Northeim, Germany) were invited to participate in the study. All residents of the nursing homes respectively their legal guardians, mostly relatives, were asked to participate. The inclusion criteria were: age; older than 55 years and living in nursing homes in the area of Goettingen and Northeim and written informed consent by nursing home residents themselves of their legal guardian. Exclusion criteria were: feeding through percutaneous endoscopic gastrostomy tube (PEG tube) and the inability to cooperate for the oral examination.

\section{Recording of subject data}

Participants' health data were obtained from resident's health record of the nursing home. The following aspects were recorded: age, gender, bedridden (yes or no), diagnosed dementia (yes or no), weight and height and active smoking (yes or no). No additional tests, e.g. to grade the severity of dementia, were performed.

\section{Assessment of nutritional condition}

The nutritional condition was assessed with the "Mini Nutritional Assessment "(MNA $\left.{ }^{\circ}\right)$ by the same examiner for all patients $(\mathrm{CW})[24,25]$. The MNA consist of simple measurements (weight, height, and weight loss) and brief questions; related to lifestyle, medication, and mobility and diet) and subjective assessment. The maximum score is 30 , a score $\geq 24$ indicates adequate nutritional status, a score between 17 and 23.5 risk of malnutrition and score $<17$ malnourishment.

\section{Dental examination}

All subjects were examined once by an experienced dentist $(\mathrm{CW})$ with a headlight in the room of the participants. The dental examination included dental status (DMF-T) and assessment of periodontal treatment need (PSR /PSI).

Dental findings/status (DMF-T) [26]: The DMF-T is a caries index to quantify the number of decayed teeth, missing teeth and filled teeth with values ranging from 0 to 28 without wisdom-teeth. The DMF-T was assessed visually with mirror and probe. Based on the number of decayed, missing, and filled teeth, the DMF$\mathrm{T}$ was determined as follows: All teeth with a reasonable suspicion of/or definitely showing a cavity in the dentine layer, were assigned to the D (=decayed) component; filled and crowned teeth were evaluated and assigned to component $\mathrm{F}$ (=filled); missing teeth were assigned to the $\mathrm{M}$ component (=missing). Periodontal screening (PSR/PSI) [27]: Periodontal treatment need was determined by probing depth of periodontal pocket and by extend of the resulting bleeding. The periodontal situation (periodontal 
treatment need) was evaluated with the periodontal screening index (PSR/PSI). The examination was performed with the WHO probe (Morita, Kyoto, Japan) at 6 points per tooth and the PSR/PSI score was recorded using the following criteria:

$\triangle$ PSR $^{\circ}$ PSI 0: if pocket depth $<3.5 \mathrm{~mm}$, no bleeding and no calculus.

$>$ PSR $^{\circ}$ PSI 1: if pocket depth $<3.5 \mathrm{~mm}$, bleeding on probing and no calculus.

$>$ PSR /PSI 2: if pocket depth $<3.5 \mathrm{~mm}$, bleeding on probing and calculus is present.

$\triangle$ PSR $^{\circ}$ /PSI 3: if pocket depth is $3.5-5.5 \mathrm{~mm}$.

$\triangle$ PSR $^{\circ}$ PSI 4: if pocket depth is $>5.5 \mathrm{~mm}$.

Maxilla and mandible were divided in 3 sextants: 1 of the anterior and 2 of the posterior teeth. The highest score was determined for each sextant of the dentition. $\mathrm{PSR}^{\circ} / \mathrm{PSI}$ scores between 3 and 4 stated for need for periodontal treatment.

\section{Statistical analysis}

Descriptive statistics of data are reported as the means \pm standard deviation (SD) or median and range. For univariate inferential statistical analyses $\mathrm{Chi}^{2}$-test or Fisher's exact test for categorical data and $t$-test or $U$-Test for continuous data were used. For multivariate analysis logistic regression covariates were chosen based on a reasonable frequency (at least $20 \%$ in each group), including age and gender based on a recommendation from Allison [28]. We did not include data from the MNA since the predicted outcome, being at risk for malnutrition, was based on the items form the MNA. The goodness of fit was assessed with the Hosmer Lemeshow test and for the presence of multicollinearity the Bravais-Pearson correlation coefficient was used. The software package SAS 9.4 was used for analysis.

\section{Results}

\section{Subjects}

A total of 100 nursing home residents out of 370 contacted residents in four nursing homes agreed to participate in the study. Only 90 could be examined and nutritional assessment could only be performed in 87 participants with a mean age of 84 years (8.6) [median: 85.9]. Most common reason for non-participation was the inability to obtain informed consent from patients with legal guardians. Most subjects were preadipose according to WHO [29], respectively normal findings in accordance to adaptation for geriatric patients [30] with a mean BMI of $26.2(5.0) \mathrm{kg} / \mathrm{m}^{2}$ [median: 25.1]. 55\% ( $n$ $=48$ ) of the investigated residents had a diagnosed dementia according to medical records. Five subjects were totally bedridden (Table 1 ).
Table 1 Subject characteristics [ $n=87$ ] based on chart review and interview with care giving nurse

\begin{tabular}{lll}
\hline Age in years mean (SD) [median; range] & $84.1(8.6)$ \\
& & {$[85.9 ; 56-102]$} \\
\hline Gender & Female & $68(78 \%)$ \\
& Male & $19(22 \%)$ \\
Current smoker & Non-smoker & $75(86 \%)$ \\
& Smoker & $12(14 \%)$ \\
Body-mass-index in kg/m ${ }^{2}$ & & $26.2(5.0)$ \\
mean (SD) [median; range] & & {$[25.2 ; 21.8-29.0]$} \\
Dementia & No & $39(45 \%)$ \\
(yes/no) & Yes & $48(55 \%)$ \\
Totally bedridden & No & $82(94 \%)$ \\
& Yes & $5(6 \%)$
\end{tabular}

Abbreviations: SD standard deviation

\section{Nutritional condition (MNA)}

The median value of the MNA screening was 11. About half $(52 \%)$ were at risk for malnutrition according to MNA, nobody was judged as being malnourished (Table 2). Of the 45 subjects at risk of malnutrition $80 \%$ took more than three medications and $22 \%$ needed help with meals.

\section{Dental (DMF-T) and periodontal findings (PSR $\left.{ }^{\circledR} / \mathrm{PSI}\right)$}

A total of $43(48 \%)$ of the participants, which allowed oral examination were toothless, while 47 (52\%) had remaining teeth.

The mean DMF-T of all participants was 26.4 (3.1). On average, 1.1 (2.4) teeth were carious (D-T) and 4.1 (6.5) filled (F-T); the average M-T value was 21.2 (8.8). The mean DMF-T of residents $(n=47)$ with teeth was 25.0 (3.7), showing M-T-values of 15.0 (8.3) (mean D-T: 2.0 [3.1], mean F-T: 8.0 [7.4]); 45\% participants out of these subjects have 14 or more teeth (Table 3 ).

The periodontal situation could be assessed of 38 nursing home residents. No participant with teeth was periodontal healthy (PSR ${ }^{\oplus}$ PSI score 0 ). Eight subjects (21\%) had a highest PSR $/$ PSI score of 1 or 2,16 subjects (42\%) had a PSR $/$ PSI score of 3 , while 14 subjects (37\%) had a PSR $\%$ PSI score of 4 . According to the definition, $79 \%$ of the periodontal investigated dentate patients have a periodontal treatment need (Table 3).

\section{Association of dentition and nutritional status}

In univariate analysis beside diagnosed dementia (OR 2.5 $\mathrm{CI}_{95}$ 1.1-5.6) the items from MNA (mobility, neuropsychological problems and BMI) were significantly associated with being at risk for malnutrition, in contrast to edentulous (OR $2.0 \mathrm{CI} 0.8-5.8$ ) or other factors (Table 4).

Dementia remained associated in multivariate analysis adjusting for age and sex, (OR $3.1 \mathrm{CI}_{95}$ 1.2-8.2) and 
Table 2 Results of the MNA (Mini Nutritional Assessment) screening of the participants $[n=87]$

\begin{tabular}{|c|c|c|}
\hline \multirow{3}{*}{$\begin{array}{l}\text { Declined food intake } \\
\text { over the past } 3 \text { months a }\end{array}$} & Severe decrease & $1(1 \%)$ \\
\hline & Moderate decrease & $19(21 \%)$ \\
\hline & No decrease & $67(78 \%)$ \\
\hline \multirow{4}{*}{$\begin{array}{l}\text { Weight loss during } \\
\text { the past } 3 \text { months }\end{array}$} & $>3 \mathrm{~kg}$ & $5(6 \%)$ \\
\hline & $1-3 \mathrm{~kg}$ & $14(17 \%)$ \\
\hline & no & $65(74 \%)$ \\
\hline & Unknown & $3(3 \%)$ \\
\hline \multirow[t]{3}{*}{ Mobility $^{a}$} & Bed of chair bound & $21(24 \%)$ \\
\hline & $\begin{array}{l}\text { Able to get out of bed / } \\
\text { chair but does not go out }\end{array}$ & $17(20 \%)$ \\
\hline & Goes out & $49(56 \%)$ \\
\hline \multirow{2}{*}{$\begin{array}{l}\text { Psychological stress } \\
\text { or acute disease }^{\text {a }}\end{array}$} & No & $72(83 \%)$ \\
\hline & Yes & $15(17 \%)$ \\
\hline \multirow{3}{*}{$\begin{array}{l}\text { Neuropsychological } \\
\text { problems }^{\text {a }}\end{array}$} & No problems & $39(45 \%)$ \\
\hline & Mild dementia & $26(30 \%)$ \\
\hline & $\begin{array}{l}\text { Severe dementia } \\
\text { or depression }\end{array}$ & $22(25 \%)$ \\
\hline \multirow[t]{4}{*}{ Body-mass-index } & $<19$ & $2(2 \%)$ \\
\hline & $19-21$ & $11(13 \%)$ \\
\hline & $21-23$ & 19 (22\%) \\
\hline & $>23$ & $55(63 \%)$ \\
\hline $\begin{array}{l}\text { MNA screening points } \\
\text { (median and IQR) }\end{array}$ & & $11(9-13)$ \\
\hline \multirow[t]{2}{*}{ Risk for malnutrition } & $\begin{array}{l}\text { Normal nutritional status } \\
\text { (12-14 MNA screening points) }\end{array}$ & $42(48 \%)$ \\
\hline & $\begin{array}{l}\text { At risk of malnutrition } \\
\text { (8-11 MNA screening points) }\end{array}$ & $45(52 \%)$ \\
\hline
\end{tabular}

Only the first part of MNA was performed for all patients and is therefore shown in Table 2. The second part of MNA was only executed for residents with (risk for) malnutrition

Abbreviations: IQR interquartile range

${ }^{a}$ as judged by the care giving nurse

additionally being edentulous (OR $2.8 \mathrm{CI}_{95}$ 1.1-7.3) became associated significantly (Table 4). Among those with teeth no relationship between oral health situation (DMFT or $\mathrm{PSR}^{*} / \mathrm{PSI}$ ) and risk of malnutrition was observed (Table 4). Factors associated with toothlesness are shown in Table 5. Nursing home residents with dementia were more likely to have remaining teeth (OR 2.5 $\mathrm{CI}_{95}$ 1.1-5.9; Table 5).

\section{Discussion}

\section{Summary of the main results}

A weak relationship between toothlessness and being at risk for malnutrition in nursing home residents was observed, but only became apparent after adjusting for other factors. Among those with remaining teeth the dental status (decayed and missing teeth) and periodontal health was not associated with an increased risk for malnutrition. The strongest observed risk factor was a
Table 3 Oral health of the participants $[n=87]$

\begin{tabular}{|c|c|c|c|}
\hline \multicolumn{3}{|l|}{ Parameter } & Mean (SD) [median] \\
\hline \multirow{5}{*}{$\begin{array}{l}\text { All participants } \\
(n=87)\end{array}$} & \multicolumn{2}{|c|}{ DMF-T index } & $26.4(3.1)[28]$ \\
\hline & \multicolumn{2}{|c|}{ Decayed teeth } & $1.1(2.4)[0]$ \\
\hline & \multicolumn{2}{|c|}{ Missing teeth } & $21.2(8.8)[26,5]$ \\
\hline & \multicolumn{2}{|c|}{ Filled teeth } & $4.1(6.5)[0]$ \\
\hline & \multicolumn{2}{|c|}{ Edentulous residents } & $n=41(47 \%)$ \\
\hline \multirow{9}{*}{$\begin{array}{l}\text { Residents with teeth } \\
(n=46)\end{array}$} & \multicolumn{2}{|c|}{ DMF-T index } & $25.0(3.7)[27]$ \\
\hline & \multicolumn{2}{|c|}{ Decayed teeth } & $2.0(3.1)[1]$ \\
\hline & \multicolumn{2}{|c|}{ Missing teeth } & $15.0(8.3)[15]$ \\
\hline & \multicolumn{2}{|c|}{ Filled teeth } & $8.0(7.4)[6]$ \\
\hline & \multicolumn{2}{|c|}{ Remaining teeth ( $\geq 14$ teeth) } & $n=21(45 \%)$ \\
\hline & \multirow{4}{*}{$\begin{array}{l}\text { PSI / PSR } \\
{[n=38]}\end{array}$} & Score 1 & $1(3 \%)$ \\
\hline & & Score 2 & $7(18 \%)$ \\
\hline & & Score 3 & $16(42 \%)$ \\
\hline & & Score 4 & $14(37 \%)$ \\
\hline
\end{tabular}

Abbreviations: $S D$ standard deviation

record of diagnosed dementia. Patients with dementia had more often remaining teeth compared to those without.

\section{Strengths and limitations}

This is one of few studies on oral health of elderly nursing home residents in Germany including demented and bedridden residents. It was difficult to obtain informed consent from legal guardians and perform the oral examination. Therefore we have low participation rate (27\%) of 100 from 370 potentially eligible participants of whom only from 87 all data could be obtained. This might have introduced selection bias and threaten the generalizability of the current study's findings. Although a multivariate analysis for the main outcome nutritional status was conducted, the number of subjects precludes more extensive analysis. It must be also kept in mind that this is a cross sectional study, especially relating to temporality pertaining to the presence of teeth and dementia. The amounts of collected data pertinent for malnutrition were limited by lack of resources. For the diagnosis of dementia we relied on medical records and we did not attempt to assess the severity of dementia. It is known, that oral health deficiencies are more present in severe cognitive impairment [31]. Other possible risk factors for malnutrition like depression, functional impairment, difficulties swallowing, co-morbidities and medication were not collected [15].

\section{Comparison with existing literature}

In comparing the results of the current study with the fourth and fifth German oral health study (DMS IV and $\mathrm{V})$, a representative study for German general population, similar trends in DMF-T and need for periodontal 
Table 4 Comparison of patients not at risk and at risk of malnutrition regarding general and oral parameters

\begin{tabular}{|c|c|c|c|c|c|c|c|}
\hline \multirow[t]{2}{*}{ Risk factors } & \multicolumn{2}{|l|}{ Nutritional status } & \multicolumn{3}{|c|}{ Univariate analysis } & \multicolumn{2}{|c|}{ Multivariate analysis $^{a}$} \\
\hline & $\begin{array}{l}\text { Not at risk of malnutrition } \\
\text { (12-14 MNA screening points) } \\
n=42(48 \%)\end{array}$ & $\begin{array}{l}\text { At risk of malnutrition } \\
\text { (8-11 MNA } \\
\text { screening points) } \\
n=45 \text { (52\%) }\end{array}$ & OR & $p$-value & & OR & $p$-value \\
\hline \multicolumn{8}{|l|}{ General parameters } \\
\hline Age in years [mean (SD)] & $83.1(9.3)$ & $84.9(7.3)$ & n.a. & 0.33 & & $\begin{array}{l}1.0 \\
\left(\mathrm{Cl}_{95} 0.9-1.1\right)\end{array}$ & n.s. \\
\hline Gender (female) & $31(46 \%)$ & $37(54 \%)$ & $1.1\left(\mathrm{Cl}_{95} 0.4-2.7\right)$ & 0.81 & & $\begin{array}{l}1.2 \\
\left(\mathrm{Cl}_{95} 0.4-3.8\right)\end{array}$ & n.s. \\
\hline Smoking status (yes) & & $6(50 \%)$ & $6(50 \%)$ & $\begin{array}{l}0.9 \\
\left(\mathrm{Cl}_{95} 0.3-3.1\right)\end{array}$ & 0.86 & $\begin{array}{l}0.8 \\
\left(C_{95}\right.\end{array}$ & n.s \\
\hline \multicolumn{2}{|c|}{ Dementia according to medical records (yes) } & $17(40 \%)$ & $31(60 \%)$ & $\begin{array}{l}2.5 \\
\left(\mathrm{Cl}_{95}\right. \\
1.1-5.6)\end{array}$ & 0.03 & $\begin{array}{l}3.1 \\
\left(\mathrm{Cl}_{95}\right. \\
1.2-8.2)\end{array}$ & 0.02 \\
\hline \multicolumn{2}{|c|}{$\begin{array}{l}\text { Permanently bedridden according to medical } \\
\text { records (yes) }\end{array}$} & $1(2 \%)$ & $4(9 \%)$ & $\begin{array}{l}4.0 \\
\left(\mathrm{Cl}_{95} 0.4-37\right)\end{array}$ & 0.19 & n.a. & n.a. \\
\hline \multirow{3}{*}{$\begin{array}{l}\text { Neuropsychological } \\
\text { problems according to MNA }\end{array}$} & No problems & $26(62 \%)$ & $13(29 \%)$ & \multirow[t]{3}{*}{ n.a. } & \multirow[t]{3}{*}{$<0.0001$} & \multirow[t]{3}{*}{ n.a. } & \multirow[t]{3}{*}{ n.a. } \\
\hline & Mild dementia & $14(17 \%)$ & $12(27 \%)$ & & & & \\
\hline & $\begin{array}{l}\text { Severe dementia or } \\
\text { depression }\end{array}$ & $2(2 \%)$ & $24(44 \%)$ & & & & \\
\hline \multirow{3}{*}{$\begin{array}{l}\text { Mobility according to the } \\
\text { MNA }\end{array}$} & Bed of chair bound & $1(2 \%)$ & $20(44 \%)$ & \multirow[t]{3}{*}{ n.a. } & \multirow[t]{3}{*}{$<0.0001$} & \multirow[t]{3}{*}{ n.a. } & \multirow[t]{3}{*}{ n.a. } \\
\hline & $\begin{array}{l}\text { Able to get out of bed / } \\
\text { chair but does not go out }\end{array}$ & $8(19 \%)$ & $9(20 \%)$ & & & & \\
\hline & Goes out & $33(79 \%)$ & $16(36 \%)$ & & & & \\
\hline \multicolumn{2}{|c|}{ Body-mass-index kg/m² [mean (SD)] } & $27.7(4.5)$ & $24.7(5.1)$ & n.a. & 0.005 & n.a. & n.a. \\
\hline \multicolumn{8}{|l|}{ Oral parameters } \\
\hline \multicolumn{2}{|l|}{ Edentulous } & $16(38 \%)$ & $25(56 \%)$ & \multirow{2}{*}{$\begin{array}{l}2.0 \\
\left(\mathrm{Cl}_{95}\right. \\
0.8-5.8)\end{array}$} & \multirow[t]{2}{*}{0.1} & \multirow{2}{*}{$\begin{array}{l}2.8 \\
\left(\mathrm{Cl}_{95} 1.1-7.3\right)\end{array}$} & \multirow[t]{2}{*}{0.03} \\
\hline \multicolumn{2}{|l|}{ Remaining teeth } & $26(62 \%)$ & $20(44 \%)$ & & & & \\
\hline \multicolumn{2}{|c|}{ DMF-T (only those with teeth $n=46$ ) } & $25.6(2.9)$ & $24.5(4.3)$ & n.a. & 0.34 & n.a. & n.a. \\
\hline \multirow{2}{*}{$\begin{array}{l}\text { PSI / PSR score } \\
(n=37)\end{array}$} & max. Score 1 or 2 & $5(24 \%)$ & $3(19 \%)$ & \multirow{2}{*}{$\begin{array}{l}1.3 \\
\left(\mathrm{Cl}_{95} 0.4-6.7\right)\end{array}$} & \multirow[t]{2}{*}{0.71} & \multirow[t]{2}{*}{ n.a. } & \multirow[t]{2}{*}{ n.a. } \\
\hline & $\max$. Score 3 or 4 & $16(76 \%)$ & $13(81 \%)$ & & & & \\
\hline
\end{tabular}

Abbreviations: $O R$ odds ratio, $C l_{95}$ confidence interval, $S D$ standard deviation, $M N A$ (mini nutritional assessment), n.a. not applicable, n.s. not significant

${ }^{a}$ Hosmer Lemeshow-test indicated goodness of fit $\left(\mathrm{chi}^{2} \mathrm{0.37}\right)$ and multicollinearity was excluded

Table 5 Univariate analysis of association of dental status (edentulous vs. dentulous) on different factors including age, body-mass index (BMI), risk for malnutrition, gender, smoking and dementia

\begin{tabular}{|c|c|c|c|c|c|}
\hline \multicolumn{2}{|l|}{ Parameter } & $\begin{array}{l}\text { Edentulous } \\
{[n=41]}\end{array}$ & $\begin{array}{l}\text { Dentulous } \\
{[n=46]}\end{array}$ & $\mathrm{OR}\left(\mathrm{Cl}_{95}\right)$ & $\overline{p \text {-value }}$ \\
\hline \multicolumn{2}{|c|}{ Age in years [mean (SD)] } & $84.8(8.3)$ & $83.6(8.4)$ & n.a. & 0.51 \\
\hline \multicolumn{2}{|c|}{ Body-mass-index kg/m² [mean (SD)] } & $26.0(4.8)$ & $26.3(5.2)$ & n.a. & 0.97 \\
\hline \multirow[t]{2}{*}{ Risk for malnutrition } & No $[n=42]$ & $16(38 \%)$ & $26(62 \%)$ & $2.0(0.8-5.8)$ & 0.1 \\
\hline & Yes $[n=45]$ & $25(56 \%)$ & $20(44 \%)$ & & \\
\hline \multirow[t]{2}{*}{ Gender } & Female $[n=68]$ & $33(49 \%)$ & $35(51 \%)$ & $1.9(0.8-5.0)$ & 0.16 \\
\hline & Male $[n=19]$ & $8(42 \%)$ & $11(58 \%)$ & & \\
\hline \multirow[t]{2}{*}{ Smoking status } & No $[n=75]$ & $35(47 \%)$ & $40(53 \%)$ & $0.9(0.2-3.0)$ & 0.86 \\
\hline & Yes $[n=12]$ & $6(50 \%)$ & $6(50 \%)$ & & \\
\hline \multirow[t]{2}{*}{ Dementia } & No $[n=39]$ & $24(62 \%)$ & $15(38 \%)$ & $2.5(1.1-5.9)$ & 0.03 \\
\hline & Yes $[n=48]$ & $17(36 \%)$ & $31(64 \%)$ & & \\
\hline
\end{tabular}


treatment are apparent [6, 23]. About half (47\%) of the individuals in the study (mean age: 84.1 years) were edentulous. This trend is consistent with the international literature with a prevalence range between 22 and 64\% [8, 32-36]. Furthermore, in the current study, participants with remaining teeth had a high need for periodontal treatment what also corresponds to literature; prevalence range is between 26 and $84 \%[23,37-39]$.

Furthermore, $52 \%$ of participants in the current study were at risk for malnutrition according to the MNA. Recent studies in nursing homes, which also performed the MNA, showed a higher amount of elderly with risk for malnutrition. Thereby, Amorim Sena Pereira et al. (2014) registered $66 \%$ of the evaluated elderly as malnourished or respectively at risk of malnutrition in Brazil [40]. Nazemi et al. (2014) showed that 69\% were at risk of malnutrition and 10\% were categorized as malnourished in Iran [41], while Gordon et al. (2014) registered that $30 \%$ of participants were malnourished. A further $56 \%$ were at risk for malnutrition in UK [42]. An earlier review article reported a prevalence range for undernutrition in institutionalized geriatric residents of between 1 and $83 \%$ [43], suggesting high variability between different nursing homes.

In the current study, being edentulous was only in multivariate analysis significantly associated to malnutrition. Other studies showed edentulous residents, especially without dentures, to be at higher risk for malnutrition $[44,45]$. In this respect, however, it should be acknowledged that in the current study, the prosthetic situation of edentulous residents was not covered, which might explain why edentulous residents were not at a significantly higher risk for malnutrition. It was already discussed that an improvement in nutritional status by prosthetic treatment is achievable, showing heterogeneous results [46-48]. It seems thereby clear that tooth replacement alone is not able to prevent malnutrition [48]. In contrast, dementia was associated to malnutrition in both, multivariate and univariate analysis. This is in accordance to recent literature, where an association between dementia and malnutrition is apparent $[15,49]$. It is also discussed weather malnutrition might influence the cognitive status, what might result in a higher prevalence of dementia in malnourished residents [50].

In the current study, participants with dementia were more likely to have remaining teeth. With regard to this issue there are mixed results. Several studies showed dementia to be unrelated to tooth loss $[19,20]$, while other studies showed cognitively impaired residents to have a higher prevalence of toothlessness [21, 22]. Consequently, the results of the current study are not in line with the recent literature. Only one study already found lower prevalence of toothlessness in demented patients [51]. This study also detected poor oral hygiene and health in patients with dementia [51]. Possible explanations for these findings might be an inadequate dental care after developing dementia; leading to a higher number of retained teeth, which are not worth preserving. Decayed or periodontal damaged teeth are not extracted due to decreased ability to complain about oral health problems. Additionally, frequently prescribed anticholinergic drugs, decreasing salivation, to control disturbing behaviors might add to the decay of teeth.

Further studies showed also a high need for periodontal treatment in elderly individuals with dementia [17, 18]. In this context, a potential correlation between dementia and periodontitis is recently discussed [52]. It might therefore be possible, that the higher number of remaining teeth in demented participants lead to a higher prevalence of dental and periodontal diseases. This could cause pain and problems, leading to difficulties during food intake, resulting in a higher risk of malnutrition. Therefore, improving oral hygiene in nursing home residents with remaining teeth and regular oral examination particularly for residents with dementia is desirable.

\section{Conclusion}

Beside of dementia status, being edentulous was the only dental parameter, which was weakly associated with risk for malnutrition. Overall the oral health was poor, which affected particularly nursing home residents with dementia which had more remaining teeth. Further studies to elucidate the possible role of oral health as cofactor for malnutrition in dementia are needed.

\section{Abbreviations}

BMI: Body mass index; MNA: Mini nutritional assessment; DMF-T: Decayed (D), missing (M), and filled (F) teeth (T) index; PSR ${ }^{\oplus}$ PSI: Periodontal screening index; DMS IV: Fourth German oral health study; DMS V:: Fifth German oral health study

\section{Acknowledgements}

The authors acknowledge support from the German Research Foundation (DFG) and Universität Leipzig within the program of Open Access Publishing.

\section{Funding}

The authors declare that no funding was obtained for the study.

\section{Availability of data and materials}

The data that support the findings of this study are available from [JFC] but restrictions apply to the availability of these data, which were used under license for the current study, and so are not publicly available. Data are however available from the authors upon reasonable request and with permission of [JFC].

\section{Authors' contributions}

DZ designed research, performed data analysis and interpretation and wrote the manuscript. CW performed examination of the residents and revised the manuscript. GS took part in data interpretation and revised the manuscript. IN took part in data interpretation and revised the manuscript. $\mathrm{RH}$ took part in data interpretation and revised the manuscript. RFM designed research, revised the manuscript. JFC designed research, performed data analysis and 
interpretation and wrote the manuscript. All authors meet the conditions set up by the International Committee of Medical Journal Editors (ICMJE). All authors gave final approval of the manuscript.

\section{Authors' information}

Not applicable.

\section{Competing interests}

The authors declare that they have no competing interests.

\section{Consent for publication}

Not applicable.

\section{Ethics approval and consent to participate}

This clinical cross-sectional study was reviewed and approved by the ethics committee of the University Medical Center Goettingen, Germany (No. 21/3/ 10). All participants or their legal guardian provided written informed consent. For vulnerable participants (including dementia) deemed clinically unable to give consent the guardian consent was received. Guidelines for ethical approvals for human subjects were followed in accordance with the Declaration of Helsinki.

\section{Author details}

'Department of Cariology, Endodontology and Periodontology, University of Leipzig, Liebigstr. 12, D 04103 Leipzig, Germany. ${ }^{2}$ Dental practice, Goettingen, Germany. ${ }^{3}$ Department of Prosthodontics and Materials Science, University of Leipzig, Leipzig, Germany. ${ }^{4}$ Deptartment of Preventive Dentistry, Periodontology and Cariology, University University Medical Center, Goettingen, Germany. ${ }^{5}$ Department of General Practice, Institute for Community Medicine, University Medicine Greifswald, Greifswald, Germany. ${ }^{6}$ Clinic of Geriatric and Special Care Dentistry, Center of Dentistry, University of Zurich, Zurich, Switzerland.

Received: 21 July 2016 Accepted: 21 January 2017

Published online: 31 January 2017

\section{References}

1. Müller F, Nitschke I. Oral health, dental state and nutrition in older adults. Z Gerontol Geriatr. 2005;38:334-41 [in German].

2. Saunders MJ, Stattmiller SP, Kirk KM. Oral health issues in the nutrition of institutionalized elders. J Nutr Elder. 2007;26:39-58.

3. Kluge F, Zagheni $E$, Loichinger $E$, Vogt $T$. The advantages of demographic change after the wave: fewer and older, but healthier, greener, and more productive? Plos One. 2014;9:e108501

4. Jones JA, Orner MB, Spiro A, et al. Tooth loss and dentures: patients perspectives. Int Dent J. 2003;5:327-34.

5. Fries JF. The compression of morbidity: near or far? Milbank $\mathrm{Q}$. 1989;67:208-32

6. Micheelis W, Schiffner U. The fourth German oral health study (DMS IV). In: Institut der Deutschen Zahnärzte, editor. IDZ materialienreihe band 31. Köln: Deutscher Zahnärzte Verlag DÄV; 2006 [in German].

7. Fitzpatrick J. Oral health care needs of dependent older people: responsibilities of nurses and care staff. J Adv Nurs. 2000;32:1325-32.

8. De Visschere L, Grooten L, Theuniers G, Vanobbergen JN. Oral hygiene of elderly people in longterm care institutions - a cross-sectional study. Gerodontology. 2006;23:195-204.

9. Frenkel HF, Harvey I, Newcombe RG. Oral health care among nursing home residents in Avon. Gerodontology. 2000:17:33-8.

10. Vanobbergen JN, De Visschere LM. Factors contributing to the variation in oral hygiene practices and facilities in long-term care institutions for the elderly. Community Dent Health. 2005;22:260-5.

11. Lesourd B. Protein undernutrition as the major cause of decreased immune function in the elderly: clinical and functional implications. Nutr Rev. 1995; 53:86-94.

12. Sullivan DH, Martin W, Flaxman N, Hagen JE. Oral health problems and involuntary weight loss in a population of frail elderly. J Am Geriatr Soc. 1993:41:725-31.

13. Lopez-Jornet $P$, Saura-Perez M, Llevat-Espinosa N. Effect of oral health dental state and risk of malnutrition in elderly people. Geriatr Gerontol Int. 2013;13:43-9.
14. Hildebrandt GH, Dominguez BL, Schork MA, Loesche WJ. Functional units, chewing, swallowing, and food avoidance among the elderly. J Prosthet Dent. 1997;77:588-95.

15. Bell CL, Lee AS, Tamura BK. Malnutrition in the nursing home. Curr Opin Clin Nutr Metab Care. 2015;18:17-23.

16. Moreira NC, Krausch-Hofmann S, Matthys C, Vereecken C, Vanhauwaert E, Declercq A, Bekkering GE, Duyck J. Risk factors for malnutrition in older adults: a systematic review of the literature based on longitudinal data. Adv Nutr. 2016:7:507-22.

17. Zenthöfer A, Schröder J, Cabrera T, Rammelsberg P, Hassel AJ. Comparison of oral health among older people with and without dementia. Community Dent Health. 2014;31:27-31.

18. Syrjälä AM, Ylöstalo P, Ruoppi $P$, Komulainen $K$, Hartikainen S, Sulkava R, Knuuttila M. Dementia and oral health among subjects aged 75 years or older. Gerodontology. 2012;29:36-42.

19. Chen X, Shuman SK, Hodges JS, Gatewood LC, Xu J. Patterns of tooth loss in older adults with and without dementia: a retrospective study based on a Minnesota cohort. J Am Geriatr Soc. 2010;58:2300-7.

20. Elsig F, Schimmel M, Duvernay E, Giannelli SV, Graf CE, Carlier S, Herrmann FR, Michel JP, Gold G, Zekry D, Müller F. Tooth loss, chewing efficiency and cognitive impairment in geriatric patients. Gerodontology. 2015:32:149-56.

21. Okamoto N, Morikawa M, Okamoto K, Habu N, Iwamoto J, Tomioka K, Saeki K, Yanagi M, Amano N, Kurumatani N. Relationship of tooth loss to mild memory impairment and cognitive impairment: findings from the Fujiwarakyo study. Behav Brain Funct. 2010;31(6):77.

22. Luo J, Wu B, Zhao Q, Guo Q, Meng H, Yu L, Zheng L, Hong Z, Ding D. Association between tooth loss and cognitive function among 3063 Chinese older adults: a community-based study. Plos One. 2015:10: e0120986.

23. Jordan RA, Micheelis W. The fifth German oral health study (DMS V). In: Institut der Deutschen Zahnärzte, editor. IDZ materialienreihe band 35. Köln: Deutscher Zahnärzte Verlag DÄV; 2016 [in German].

24. Guigoz Y, Vellas B, Garry PJ. Mini nutritional assessment: a practical assessment tool for grading the nutritional state of elderly patients. Facts Res Gerontol. 1994;Supplement:11-59.

25. Vellas B, Guigoz Y, Garry PJ, Nourhashemi F, Bennahum D, Lauque S, Albarede $J$. The mini nutritional assessment (MNA) and its use in grading the nutritional state of elderly patients. Nutrition. 1999;15:116-22.

26. WHO. World Health Organization: oral health surveys, basic methods. 4th ed. Genf: WHO; Oral Health Unit; 1997.

27. Meyle J, Jepsen S. The periodontal screening-index (PSI). Parodontol. 2000 11:17-21 [in German].

28. Allison PD. Multiple regression: a primer (research methods and statistics). 1999. Pine Forge Press Series in Res

29. WHO. World Health Organization Obesity: preventing and managing the global epidemic. Report of a WHO consultation. 2000;894:i-xii, 1-253. Epub 2001/03/10

30. Rojer AG, Kruizenga HM, Trappenburg MC, Reijnierse EM, Sipilä S, Narici MEAN, Hogrel JY, Butler-Browne G, MCPhee JS, Pääsuke M, Meskers CG, Maier AB, de van der Schueren MA. The prevalence of malnutrition according to the new ESPEN definition in four diverse populations. Clin Nutr 2015 Jun 20 doi: 10.1016/j.clnu 2015.06.005. [Epub ahead of print]

31. Rejnefelt I, Andersson P, Renvert S. Oral health status in individuals with dementia living in special facilities. Int J Dent Hyg. 2006:4:67-71.

32. Hopcraft MS, Morgan MEAN, Satur JG, Wright FA. Edentulism and dental caries in victorian nursing homes. Gerodontology. 2012;29:512-9.

33. Simunković SK, Boras W, Pandurić J, Zilić IA. Oral health among institutionalised elderly in Zagreb, Croatia. Gerodontology. 2005;22:238-41.

34. Rabiei M, Kasemnezhad E, Masoudi rad H, Shakiba M, Pourkay H. Prevalence of oral and dental disorders in institutionalised elderly people in Rasht, Iran. Gerodontology. 2010;27:174-7.

35. Northridge ME, Ue FV, Borrell LN, De La Cruz LD, Chakraborty B, Bodnar S, Marshall S, Lamster IB. Tooth loss and dental caries in community-dwelling older adults in northern Manhattan. Gerodontology. 2012;29:464-73.

36. Montal S, Tramini P, Triay JA, Valcarcel J. Oral hygiene and the need for treatment of the dependent institutionalised elderly. Gerodontology. 2006; 23:67-72.

37. Gluhak C, Arnetzl GV, Kirmeier R, Jakse N, Arnetzl G. Oral status among seniors in nine nursing homes in Styria, Austria. Gerodontology. 2010;27:47-52.

38. Hopcraft MS, Morgan MEAN, Satur JG, Wright FA, Darby IB. Oral hygiene and periodontal disease in victorian nursing homes. Gerodontology. 2012;29:220-8. 
39. Samson H, Strand GV, Haugejorden O. Change in oral health status among the institutionalized Norwegian elderly over a period of 16 years. Acta Odontol Scand. 2008;66:368-73.

40. Amorim Sena Pereira ML, de Almeida MP, Cunha De Oliveira C, Carneiro Roriz AK, Teresópolis Reis Amaral M, Lima Mello A, Barbosa Ramos L. Nutritional status of institutionalized elderly Brazilians: a study with the mini nutritional assessment. Nutr Hosp. 2014;31:1198-204.

41. Nazemi L, Skoog I, Karlsson I, Hosseini S, Mohammadi MR, Hosseini M, Hosseinzade MJ, Mesbah-Namin SA, Baikpour M. Malnutrition, prevalence and relation to some risk factors among elderly residents of nursing homes in Tehran, Iran. Iran J Public Health. 2015;44:218-27.

42. Gordon AL, Franklin M, Bradshaw L, Logan P, Elliott R, Gladman JR. Health status of UK care home residents: a cohort study. Age Ageing. 2014;43:97-103.

43. Adil A, Abbasi MD, Rudmann D. Undernutrition in the nursing home: prevalence, consequences, causes and prevention. Nutr Rev. 1994:52:113-20.

44. Lamy M, Mojon P, Kalykakis G, Legrand R, Butz-Jorgensen E. Oral status and nutrition in the institutionalized elderly. J Dent. 1999;27:443-8.

45. Cousson PY, Bessadet M, Nicolas E, Veyrune JL, Lesourd B, Lassauzay C. Nutritional status, dietary intake and oral quality of life in elderly complete denture wearers. Gerodontology. 2012;29:685-92.

46. Shinkai RS, Hatch JP, Rugh JD, Sakai S, Mobley CC, Saunders MJ. Dietary intake in edentulous subjects with good and poor quality complete dentures. J Prosthet Dent. 2002;87:490-8.

47. Sahyoun NR, Lin CL, Krall E. Nutritional status of the older adult is associated with dentition status. J Am Diet Assoc. 2003;103:61-6.

48. Wöstmann B, Michel K, Brinkert B, Melchheier-Weskott A, Rehmann P, Balkenhol M. Influence of denture improvement on the nutritional status and quality of life of geriatric patients. J Dent. 2008;36:816-21.

49. Volkert D, Chourdakis M, Faxen-Irving G, Frühwald T, Landi F, Suominen MH, Vandewoude M, Wirth R, Schneider SM. ESPEN guidelines on nutrition in dementia. Clin Nutr. 2015;34:1052-73.

50. Sanders C, Behrens S, Schwartz S, Wengreen H, Corcoran CD, Lyketsos CG, Tschanz JT. Nutritional status is associated with faster cognitive decline and worse functional impairment in the progression of dementia: the cache county dementia progression study. J Alzheimers Dis. 2016;52:33-42.

51. Chen $\mathrm{X}$, Clark JJ, Naorungroj S. Oral health in nursing home residents with different cognitive statuses. Gerodontology. 2013;30:49-60.

52. Gaur S, Agnihotri R. Alzheimer's disease and chronic periodontitis: is there an association? Geriatr Gerontol Int. 2015;15:391-404.

\section{Submit your next manuscript to BioMed Central and we will help you at every step:}

- We accept pre-submission inquiries

- Our selector tool helps you to find the most relevant journal

- We provide round the clock customer support

- Convenient online submission

- Thorough peer review

- Inclusion in PubMed and all major indexing services

- Maximum visibility for your research

Submit your manuscript at www.biomedcentral.com/submit

CBiomed Central 